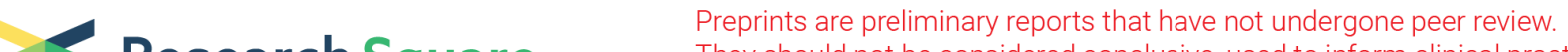 Research Square They should not be considered conclusive, used to inform clinical practice, or referenced by the media as validated information.
}

\section{Added Value of Diaphragm Myofascial Release on Forward Head Posture and Chest Expansion in Patients With Neck Pain: A Randomized Controlled Trial}

\section{Farzaneh Haghighat}

Department of Physical Therapy, School of Rehabilitation Sciences, Shiraz University of Medical Sciences, Shiraz, Iran. 2 Rehabilitation Sciences Research Center, Shiraz University of Medical Sciences, Shiraz, Iran.

\section{Razieh Moradi}

Shiraz University of Medical Sciences

Mohammadreza Rezaie

Shiraz University of Medical Science https://orcid.org/0000-0002-1996-9781

\section{Nastaran Yarahmadi}

Shiraz University of Medical Sciences

\section{Farahnaz Ghaffarnejad ( $\nabla$ fghafarinejad@yahoo.com )}

Department of Physical Therapy, School of Rehabilitation Sciences, Shiraz University of Medical Sciences, Shiraz, Iran. 2 Rehabilitation Sciences Research Center, Shiraz University of Medical Sciences, Shiraz, Iran.

\section{Research article}

Keywords: Diaphragm, myofascial release, neck pain, forward head posture, chest expansion

Posted Date: September 8th, 2020

DOl: https://doi.org/10.21203/rs.3.rs-53279/v1

License: (9) (i) This work is licensed under a Creative Commons Attribution 4.0 International License. Read Full License 


\section{Abstract}

Background: Despite the increasing use of diaphragm myofascial release technique in clinical practice, there is no study on the effect of this technique on musculoskeletal outcomes of patients with neck pain. The purpose of this study was to evaluate the added value of diaphragm myofascial release on forward head posture, chest expansion, and functional disability in patients with neck pain.

Methods: In this randomized controlled trial, 46 women with neck pain between the age of 18 and 45 years old were randomly allocated to two groups; the intervention group received 4 diaphragm myofascial release techniques once a week, for 4 weeks. Both intervention and control groups received the same neck exercise program 3 times a week for 4 weeks. Forward head posture, chest expansion, and neck functional disability were measured using craniovertebral angle, circometry, and Copenhagen neck functional disability index, respectively, before and one day after treatment.

Results: The results of the paired t-test showed significant increases in craniovertebral angle (control and intervention: $\mathrm{P}<0.001$ ) and chest expansion (control: $P=0.001$, intervention $<0.001$ ) and a significant decrease in the functional disability score (control and intervention: $P<0.001$ ) of patients with neck pain in both groups. A significant greater craniovertebral angle $(P=0.01)$ and chest expansion $(P=0.03)$ were also seen in the intervention group compared with the controls.

Conclusion: Adding diaphragm myofascial release to neck exercises was associated with significantly greater improvements in forward head posture and chest expansion than neck exercises alone. Therefore, the diaphragm myofascial release could be useful in the management of neck pain patients with FHP.

Trial registration: IRCT20191116045461N1 (Iranian Registry of Clinical Trials). Registered 23 December 2019, https://en.irct.ir/trial/43741.

\section{Introduction}

Neck pain is one of the most common, disabling, and costly musculoskeletal disorders among people of all ages with a 12-month prevalence of $30 \%-50 \%$ in the general population and is more prevalent among women (1). Maintaining the same incorrect posture for a long period of time is the main reason for neck pain. Overuse of smartphones and computers or long hours of working at desks are some of the greatest reasons for incorrect postures leading to neck pain (2).

Abnormal posture induces biomechanical changes in people with neck pain, the prominent one of which is forward head posture (FHP) (3), and is characterized by hyperextension of the upper cervical (C1-3) and flexion of the lower cervical vertebrae (C4-7) (4). In this posture, the head is not in line with the vertical axis of the body and the cervical spine is in a protracted position. These alterations induce more gravitational load on the cervical motion segments which subsequently need more muscular effort to balance the head against this load even in the cervical resting posture. Higher muscular effort results in not only myofascial pain, but also a compressive load of the cervical spine (5). According to Janda (6), FHP and round shoulder posture occur simultaneously, creating a condition known as upper crossed syndrome. These postural changes induce muscle imbalances in which some muscles such as levator scapulae, sternocleidomastoid, anterior scalene, 
posterior cervical extensor, upper trapezius and pectoralis muscles become short or stiff and some others such as deep cervical neck flexor, rhomboid, and serratus anterior muscles become inhibited or weak. Postural alterations of the cervical and thoracic spine can result in impaired chest expansion and length-tension curve of the diaphragm, thereby inducing respiratory dysfunction $(7,8)$. Under these circumstances, accessory respiratory muscles such as SCM and anterior scalene become overactive $(9,10)$. Faulty breathing pattern has been reported in $84 \%$ of patients with chronic neck pain (9).

It should be noted that long term FHP makes those accessory respiratory muscles weak, too and finally aggravates the respiratory complications.

On the other hand, the phrenic nerve which provides the sensory and motor control of the diaphragm originates from $\mathrm{C} 3-\mathrm{C} 5$ and sometimes $\mathrm{C} 6$ nerve roots and passes through the fascia of the anterior scalene. Overloading of this muscle that is commonly seen in FHP compresses the phrenic nerve over time and may eventually lead to the trophic changes of the phrenic nerve and resultant diaphragm dysfunction (11). Due to the common cervical nerve roots, any disorder to the phrenic nerve or the structures supplied by the phrenic nerve such as diaphragm can affect other neurons at the same level like the axillary nerve, suprascapular nerve, musculotendinous and subclavian nerve; also any injury to these nerves and the muscles innervated by them can affect the phrenic nerve and diaphragm. For example, overactive scalene muscles that receive innervation from C4-C6 cervical nerve roots in neck pain patients with FHP can modify the function of the phrenic nerve and diaphragm negatively $(11,12)$.

Furthermore, it is proposed that there is a fascial bridge between the cervical region and diaphragm muscle through transversalis and thoracolumbar fascia. Due to this mechanical connection, any anomalous muscular tension in the diaphragm or neck muscles can negatively affect the other (12).

Based on the above points, it seems that the FHP not only causes pain and breathing problems in patients with neck pain, but also the existence of a vicious cycle between this posture and resultant respiratory problems can make this situation worse. Therefore, breaking this cycle is very important, and it seems that correcting this posture is a priority in treating these patients and reducing their disability. So far, studies in this area all have examined the effect of exercise and other local physical therapies in the neck area on FHP. The functional, neurological, and fascial interdependent relationship between the diaphragm and the cervical spine can be a basis for the use of manual treatments such as myofascial release on the diaphragm to affect the cervical spine.

Myofascial release of the diaphragm is an intervention intended to indirectly stretch the diaphragm muscle fibers to reduce muscle tension, normalize fiber length, and promote the efficiency of muscle contraction (13). Although diaphragm myofascial release has been used in clinical practice, to the best of the authors' knowledge, the current study is the first research investigating the effect of diaphragm release on FHP and chest expansion in patients with neck pain. Therefore, the purpose of this study was to assess the effect of diaphragm myofascial release on FHP, chest expansion, and functional disability of patients with neck pain. We hypothesized that this therapeutic technique could help balance the muscles around the neck and improve the cervical spine posture in these patients through diaphragm neurological and fascial communication with the cervical spine and restoring normal mobility to the chest. If effective, this, in turn, improves breathing 
efficacy, reducing the load on the accessory respiratory muscles in the neck and improving the performance of the diaphragm as the main breathing muscle

\section{Method}

\section{Design}

The present study was a parallel-group randomized controlled trial. Patients recruitment and data collection were conducted between December 2019 to April 2020.

\section{Participants}

Patients with neck pain were recruited from physiotherapy and orthopedic clinics under the supervision of the Shiraz University of Medical Science and selected by convenient sampling method. Potential participants were first assessed for eligibility by a physiotherapist. The inclusion criteria were: 1) women between 18 and 45 years old, 2) mechanical neck pain without referral signs lasting for at least 3 months, 3) the craniovertebral angle less than 49 degrees, 4) reporting pain on palpation of the diaphragm, and 5) usage of smartphone and computer for an average of 4 hours or more a day.

The exclusion criteria were: 1) Auditory or visual impairments., 2) Balance or any neurological impairments, 3) History of neck surgery, 4) History of any trauma or fracture to the cervical spine, clavicle, scapula, and ribs, 5) Inflammatory diseases such as rheumatoid arthritis, 6) A congenital deformity in the neck such as torticollis, 7) Respiratory disease and Zona, and 8) doing any regular exercise for the last 6 months.

Interventions

The intervention group received both the diaphragm myofascial release technique and an exercise program, while the control group only received the same exercise program.

To release the diaphragm, the patient was positioned in the supine position. The therapist stood at the head of the patient. The therapist made manual contact bilaterally under the costal cartilages of the lower ribs (7th to 10th ) with hypothenar regions of the hands and last three fingers. During the patient's inspiration, the therapist was gently pulling the points of hands contacts toward the head and slightly laterally, while elevating the ribs simultaneously. During exhalation, the therapist deepened hand contacts towards the inner costal margins, (14). The release technique was performed once a week for four weeks; each technique lasted for 5 to 7 minutes (15). All release techniques were done by the same physiotherapist.

The exercise program included the strengthening of the deep cervical flexor and shoulder retractor muscles and also stretching of the pectoralis and cervical extensor muscles. Both groups received the exercise program 3 days a week for four weeks. The complete exercises for each muscle group in addition to the duration and repetition are listed in Table 1. 
Table 1

neck exercise program

\begin{tabular}{|c|c|}
\hline Exercise & Measures \\
\hline $\begin{array}{c}\text { Strengthen Deep Cervical Flexors } \\
\text { Lying chin tuck } \\
\text { Lying chin tuck with head lift (4 s) }\end{array}$ & 3 sets of 12 repetitions \\
\hline Strengthen Shoulder Retractors & 3 sets of 12 repetitions \\
\hline Standing shoulder pull back with elastic & 3 sets of 12 repetitions \\
Resistance shoulder pull back with weight (2 lb.) & 3 sets of 12 repetitions \\
\hline Stretch Cervical Extensors & 3 repetitions with 30-sec hold \\
\hline Chin drop & \\
\hline Stretch Pectoralis Muscle & 3 repetitions with 30-sec hold \\
\hline Bilateral Pectoral stretch
\end{tabular}

\section{Outcomes}

The data collection was done in two steps. The first step was before starting the treatment and the second step was one day after the end of the treatment period (4 weeks). The primary outcome was head posture measurement and the secondary outcomes were the extent of chest expansion and the level of functional disability.

Craniovertebral angle (CVA): CVA was measured to assess the head posture. It is the angle between the line connecting the middle point of the ear tragus to $\mathrm{C} 7$ and the horizontal line that passes through the $\mathrm{C} 7$ (Fig. 1). CVA shows the position of the head relative to the C7 vertebra, which in patients with FHP is less than 49 degrees; the lower measured angle shows severe FHP. To determine the exact place of the $\mathrm{C} 7$ spinous process, patients were asked to bend their neck forward. This bony landmark becomes prominent in this position and this region was checked in a relaxed neck position, too; then, a marker was attached there. In the present study, this angle was measured using photography from the left sagittal view. A digital camera with a 35-70 zoom lens was placed on a tripod and the lens aperture and the zoom were set to the F-stop8 and $70 \mathrm{~mm}$, respectively. The center of the lens was 4 meters away from the individuals with the subject in approximately the center of the lens to reduce the lens error. To minimize the parallax error, the camera was positioned perpendicular to the ground and parallel with the subject's pelvis. A set square was placed 90 degrees on the wall behind the subjects to determine the proper frame angle for camera placement. To ensure that the head does not rotate, a circular frame, parallel to the patient's eye, was attached to the wall in front of the patient's eyes, and the patient was asked to look at it. The patient's neck and upper thoracic area was naked and was photographed from the same distance. The same conditions will apply to everyone taking photos. These configurations were adjusted for each subject. Participants were asked to stand straight and comfortable, with straight knees and half of their body weight on each foot, the hands hanging beside the body, shoulder-width legs apart, and looking forward eyes. Also, to capture their natural posture, they were asked to relax and not to 
keep their posture in an erected or straight position (16). After capturing, the photos were transferred to a laptop and the CVA angle was extracted by Image $\mathrm{J}$ software (https://imagej.nih.gov/ij/). High reliability was reported for CVA measurement in a previous study (16).

Chest expansion (CE) measurement: The patient was asked to put her hands on the head during the standing position. The starting point of a tape measure was placed on the xiphoid process and then wrapped around the chest. The assessor measured the circumference of the patient's chest (at xiphoid level) after maximum possible inhalation and exhalation, respectively (17). The difference between these two values shows the amount of chest expansion. Mohan et Al. reported the reliability of this method as excellent (ICC >0.85 and SEMs $<5 \%)(18)$.

Copenhagen Neck Function Disability Scale (CNFDS): CNFDS is a self-administered questionnaire developed to measure the level of functional disabilities due to neck pain. In this scale, 2 items measure pain intensity, 9 items evaluate disability daily activities, and 5 items measure social interactions and recreational activities. Three possible answers are considered for each item: Yes, Sometimes, and No. The total score ranges from 0 to 30 . The higher the score, the greater the disability. The validity and reliability of the Persian version of CNFDS were checked by Ghasemi et Al. (Cronbach alpha $=0.92$, Test-retest reliability $=0.86)(19)$.

Sample size

The sample size of the present study was calculated based on the CAV standard deviation from a previous study. Considering a power of $80 \%$, a significance level of 0.05 , and a $10 \%$ drop-out rate, the number of participants needed in each group was estimated to be 26.

\section{Randomization}

Eligible patients with neck pain were randomly divided into two groups (intervention and control) by the blocked-randomization method. Six blocks with the size of four were taken into account.

\section{Blinding}

Sequentially numbered opaque, sealed, and stapled envelopes (SNOSE) were used to conceal the allocation procedure from the examiner. The randomization process was done by a person different from the therapists and examiner. All interventions were done by an expert physiotherapist who was different from the examiner.

Statistical methods

The normal distribution of the dataset was tested by the Shapiro-Wilk test and all data followed a normal distribution. The Paired T-test was used to compare the values of pre- and post-treatment for each group. The mean differences between the values of pre-treatment and post-treatment were used for statistical analysis. Between-group comparison was done by Independent sample T-test. All statistical analyses were performed by SPSS software (version 21; SPSS, Inc., Chicago, IL) and the significance level of alpha was considered to be 0.05 .

\section{Results}


46 out of 52 participants ( 22 control and 24 intervention) completed the treatment for a duration of 4 weeks (Fig. 2). The baseline characteristics of participants in each group are summarized in Table 2. This Table shows that there is no significant difference in age, height, weight, and pain duration between the two groups $(P>0.05)$.

Table 2

Baseline characteristics of the intervention and control groups

\begin{tabular}{|llll|}
\hline & Control $(\mathbf{n}=\mathbf{2 2})$ & Intervention $(\mathbf{n}=\mathbf{2 4})$ & P-value \\
\hline Age (years) & $26.91(8.02)$ & $27.42(7.48)$ & 0.82 \\
\hline Height (centimeter) & $160.45(4.55)$ & $161.62(7.55)$ & 0.52 \\
\hline Weight (kilogram) & $56.81(8.88)$ & $57.54(8.85)$ & 0.78 \\
\hline Pain duration (month) & $26.36(28.08)$ & $23.96(19.2)$ & 0.73 \\
\hline
\end{tabular}

The results of the Paired T-test showed significant differences for CVA (control and intervention: $P<0.001$ ), CE (control: $P=0.001$, intervention $<0.001$ ), and CNFDS (control and intervention: $P<0.001$ ). The results of the Independent sample T-test showed significant differences for CVA $(1.47 \pm 0.55, P=0.01)$ and CE $(0.81 \pm 0.35$, $P=0.03)$, but not for CNFDS $(-0.5 \pm 1.13, P=0.66)$ (Table 3$)$.

Table 3

Intra- and inter-group differences in the CVA, CE, and CNFDS

\begin{tabular}{|c|c|c|c|c|c|c|c|}
\hline & \multicolumn{2}{|c|}{ Control $(n=22)$} & \multicolumn{2}{|c|}{ Intervention $(n=24)$} & \multicolumn{3}{|c|}{ Between-group difference } \\
\hline & Mean (SD) & P-value & Mean (SD) & P-value & $\begin{array}{l}\text { Mean } \\
\text { (SD) }\end{array}$ & $\begin{array}{l}95 \% \\
\mathrm{Cl}\end{array}$ & $\begin{array}{l}\mathrm{P}- \\
\text { value }\end{array}$ \\
\hline \multicolumn{8}{|l|}{ CVA } \\
\hline Pre & $44.32(4.32)$ & \multirow{2}{*}{$\begin{array}{l}\mathrm{P}< \\
0.001^{\star \star \star}\end{array}$} & $44.99(3.29)$ & \multirow{2}{*}{$\begin{array}{l}\mathrm{P}< \\
0.001^{\star \star \star}\end{array}$} & \multirow[t]{2}{*}{$1.47(0.55)$} & \multirow{2}{*}{$\begin{array}{l}0.36- \\
2.58\end{array}$} & \multirow{2}{*}{$0.01^{*}$} \\
\hline Post & $46.45(3.88)$ & & $48.6(3.12)$ & & & & \\
\hline \multicolumn{8}{|l|}{ CE } \\
\hline Pre & $3.72(0.93)$ & \multirow[t]{2}{*}{$0.001^{\star *}$} & $3.58(0.93)$ & \multirow{2}{*}{$\begin{array}{l}\mathrm{P}< \\
0.001^{\star \star \star}\end{array}$} & \multirow[t]{2}{*}{$0.81(0.35)$} & \multirow{2}{*}{$\begin{array}{l}0.09- \\
1.53\end{array}$} & \multirow[t]{2}{*}{$0.027^{\star}$} \\
\hline Post & $4.5(1.14)$ & & $5.17(1.37)$ & & & & \\
\hline \multicolumn{8}{|l|}{ CNFDS } \\
\hline Pre & $8.72(5.27)$ & \multirow{2}{*}{$\begin{array}{l}\mathrm{P}< \\
0.001^{\star \star \star}\end{array}$} & $9.33(5.77)$ & \multirow{2}{*}{$\begin{array}{l}\mathrm{P}< \\
0.001^{\star \star \star}\end{array}$} & \multirow[t]{2}{*}{$-0.5(1.13)$} & \multirow{2}{*}{$\begin{array}{l}-2.77- \\
1.78\end{array}$} & \multirow[t]{2}{*}{0.659} \\
\hline Post & $4.72(4.18)$ & & $4.83(4.26)$ & & & & \\
\hline \multicolumn{8}{|c|}{ CVA: CranioVertebrae Angle, CE: Chest Expansion, CNFDS: Copenhagen Neck Function Disability Scale. } \\
\hline \multicolumn{8}{|c|}{$\star: P<0.05, * *: P<0.01, * \star *: P<0.001$} \\
\hline
\end{tabular}

\section{Discussion}


The purpose of the present randomized controlled trial was to evaluate the added value of diaphragm myofascial release on FHP, chest expansion, and functional disability in patients with neck pain. The results indicated that combining diaphragm myofascial release with an exercise program led to greater improvements in FHP and chest mobility compared to exercises alone and thus demonstrated an additional benefit of diaphragm myofascial release in neck pain patients with FHP. Although both groups demonstrated improved FHP, chest expansion, and functional disability score after treatment, patients in the experimental group demonstrated significantly greater improvements in FHP and chest mobility. No significant differences were observed for functional disability score between the groups.

As far as we know, this is the first study evaluating the effect of diaphragm myofascial release on FHP, chest expansion, and functional disability in patients with neck pain, so it is difficult to compare the results of the present study directly with the previous researches.

The functional disability score assessed by CNFDS improved in both groups after treatment without any difference between the groups. This finding is in accordance with previous research evaluating the effect of exercise on neck pain and disability (20). It is proposed that exercise therapy improves the neuromuscular function and restores the sensorimotor control of the normal movement patterns of the neck. According to the gate control theory, stimulation of these mechanoreceptors increases the afferent nerve activity, which, in turn, inhibits the activity of small-diameter pain nerves (21). Also, since this questionnaire items assess the pain during different functional activities, this finding confirms the results of the study by McCoss et al. (22) which investigated the immediate effects of diaphragm myofascial release on pain pressure thresholds in the cervical spine and found that diaphragm release could induce an immediate hypoalgesic effect at the cervical spine. It is suggested that mechanical stimulation of the diaphragm activates the mechanoreceptors in the diaphragm and subsequently the phrenic nerve which contains large diameter afferent neuron. This information is then transferred to the dorsal horn of the spinal cord and synapse with inhibitory interneurons, resulting in hypoalgesia in the somatic tissues supplied by those cervical segments (22-25).

Improved chest expansion was observed after treatment in both groups. Improved xiphoid level chest expansion after diaphragm myofascial release is consistent with the findings of previous studies $(14,15,26)$ and could be partially related to diaphragm attachments. Muscular fibers of the diaphragm are attached to the sternum (xiphoid process), lower 6 ribs, and lumbar vertebrae (the L1, L2, and L3 vertebrae and arcuate ligaments) (12). Thus, the dysfunction of the diaphragm may reasonably be expected to interfere with optimal rib cage mobility, and decreasing stiffness of the diaphragm would allow a greater rib cage motion.

The control group also showed a significant increase in the chest expansion after exercise therapy. In a previous study, a physical therapy program including exercise therapy could improve chest mobility in neck pain patients (27). Regarding the effect mechanism of neck exercise on ribcage mobility, it can be said that any muscle attached to the chest wall can influence its mobility to some degree. For example, weakness of upper back erector spinae and middle and lower trapezius muscle reduces the ability to straighten the upper back, thus interfering with the ability to expand the chest. Moreover, thoracic spine and rib cage motions are found to be interdependent. When there is a thoracic kyphosis or round shoulder, as they are common postural malalignment in the patients with neck pain, the ribs are depressed and the chest mobility is limited $(27,28)$. Therefore, exercises aiming at strengthening the shoulder retractors and stretching the pectoralis muscles 
which were used in the current study can help with extension of the thoracic spine, elevation of the ribs, and improving chest expansion.

The results showed that combining the diaphragm release with exercise therapy caused a significantly greater chest expansion in the intervention group compared to the control group. This finding could be related to the fact that the diaphragm attaches directly to the Xiphoid process and the lower ribs, so not only chest mobility was improved with exercise therapy through straightening the upper back and extending the thoracic vertebrae, but also it was improved by releasing the tension on the diaphragm and allowing the xiphoid and lower ribs move more freely. Therefore, greater chest mobility due to the cumulative effects of both treatments in the experimental group compared to the controls seems reasonable.

Greater improvements of FHP in the intervention compared to the control group was the most interesting finding of the present study. The positive effect of neck exercise therapy on FHP is well documented in previous studies (29). There are several possible mechanisms for greater improvement in FHP in the intervention group compared to controls. First, as mentioned earlier, the neck and diaphragm are mechanically connected through the thoracolumbar and transversalis fascia (12). Hence, the altered tone of the neck muscles will affect the diaphragm's function and vice versa (11). It is documented that neck pain patients especially those with FHP, suffer from respiratory problems influenced by thoracic spine kyphosis and chest hypomobility $(7,30-32)$. Thus, the diaphragm length-tension relationship could be affected $(7,26,32)$. Combining the diaphragm release with the therapeutic exercise in the intervention group might relieve the tension on the tight neck muscles more effectively compared to the control group which only received the exercise therapy.

Second, the intervention group probably experienced more pain relief by combining the diaphragm release with neck exercise compared with the control group and this may help to decrease neck muscle tension and spasm. Moreover, reduction in pain corresponds well to the increased number of active muscle fibers (27) and this may help the weak muscles to partially restore their strength. Overall, these mechanisms may help patients in adopting a better posture.

Third, due to the interdependency between chest expansion, thoracic kyphosis, and FHP (33), it can be said that improving chest expansion to a greater degree in the intervention group could be a basis for greater improvement in FHP in this group.

And finally, it can be said that the diaphragm, by restoring a more normal length-tension relationship and also due to better mobility and expansion in the chest wall, can participate more efficiently in breathing, and it may help to relieve the load on accessory respiratory muscles in the neck and subsequently improve FHP.

FHP which is associated with decreased chest expansion is the most common postural deformity affecting respiration (7). Improved rib cage expansion and FHP to a greater degree in the experimental group which received combined diaphragm myofascial release and exercise therapy, compared to the control group that received only the exercise therapy, suggests that the diaphragm release technique might be a valuable addition to the rehabilitation of patients with chronic neck pain to improve their respiratory function. 
The present study had some limitations. Only the females with neck pain were included in this study which makes it difficult to generalize the results to men. Another limitation was the absence of follow-up to determine whether the improvements in the outcome measures were maintained in the long term. Further research is needed to follow the long-term effects of diaphragm myofascial release in neck pain patients with FHP.

\section{Conclusions}

The results of the current study showed that combining diaphragm myofascial release with neck exercises was associated with significantly greater improvements in forward head posture and chest expansion than neck exercises alone. Therefore, diaphragm myofascial release could be useful in the management of neck pain patients with FHP.

\section{Abbreviations}

FHP

Forward Head Posture, CVA:Craniovertebrae Angle, CE:Chest Expansion, CNFDS:Copenhagen Neck Function Disability Scale.

\section{Declarations}

\section{Ethics approval and consent to participate}

This study was approved by the research ethics committee of the Shiraz University of Medical Science in Iran (No. IR.SUMS.REHAB.REC.1397.022) and also registered prospectively in the Iranian Registry of Clinical Trials (No. IRCT20191116045461N1). Written informed consent was obtained from all the participants before they participated in this study.

\section{Consent for publication}

Not applicable

\section{Availability of data and materials}

Accessing to the dataset of this study will be available by contacting the corresponding author (FG).

\section{Competing interests}

The authors declare that they have no competing interests.

Funding

This article was supported financially by Shiraz University of Medical Sciences (grant No. 97-01-51-18913).

\section{Authors' contributions}


All authors participated in the conception and design of the study. RM, NY, and FH were responsible for the acquisition of data. FH, FG, MR analyzed and interpreted the data. FH and MR drafted the manuscript, FH, MR, and FG critically revised the manuscript for important intellectual content. All authors approved the final version of the manuscript.

\section{Acknowledgments}

We thank Dr. Nasrin Shokrpour at the Research Consultation Center (RCC) of Shiraz University of Medical Sciences for improving the use of English in the manuscript.

\section{References}

1. Hogg-Johnson S, Van Der Velde G, Carroll LJ, Holm LW, Cassidy JD, Guzman J, et al. The burden and determinants of neck pain in the general population. Eur Spine J. 2008;17(1):39-51.

2. Tunwattanapong P, Kongkasuwan R, Kuptniratsaikul V. The effectiveness of a neck and shoulder stretching exercise program among office workers with neck pain: a randomized controlled trial. Clinical rehabilitation. 2016;30(1):64-72.

3. Ruivo R, Carita A, Pezarat-Correia P. The effects of training and detraining after an 8 month resistance and stretching training program on forward head and protracted shoulder postures in adolescents: Randomised controlled study. Man Therap. 2016;21:76-82.

4. Ohmure H, Miyawaki S, Nagata J, Ikeda K, Yamasaki K, Al-Kalaly A. Influence of forward head posture on condylar position. J Rehabil. 2008;35(11):795-800.

5. Silva AG, Punt TD, Sharples P, Vilas-Boas JP, Johnson MI. Head posture and neck pain of chronic nontraumatic origin: a comparison between patients and pain-free persons. Arch Phys Med Rehabil. 2009;90(4):669-74.

6. Janda V. Muscles and motor control in cervicogenic disorders: assessment and management. Physical therapy of the cervical and thoracic spine. 1994.

7. Solakoğlu Ö, Yalçın P, Dinçer G. The effects of forward head posture on expiratory muscle strength in chronic neck pain patients: A cross-sectional study. Turkish Journal of Physical Medicine \& Rehabilitation. (2587 - 0823). 2020;66(2).

8. Kapreli E, Vourazanis E, Strimpakos N. Neck pain causes respiratory dysfunction. Medical hypotheses. 2008;70(5):1009-13.

9. Perri MA, Halford E. Pain and faulty breathing: a pilot study. Journal of Bodywork Movement Therapies. 2004;8(4):297-306.

10. Cagnie B, Danneels L, Cools A, Dickx N, Cambier D. The influence of breathing type, expiration and cervical posture on the performance of the cranio-cervical flexion test in healthy subjects. Man Therap. 2008;13(3):232-8.

11. Wallden M. The diaphragm-more than an inspired design. Journal of Bodywork Movement Therapies. 2017;21(2):342-9.

12. Bordoni B, Zanier E. Anatomic connections of the diaphragm: influence of respiration on the body system. Journal of multidisciplinary healthcare. 2013;6:281. 
13. Ajimsha M, Al-Mudahka NR, Al-Madzhar J. Effectiveness of myofascial release: systematic review of randomized controlled trials. J Bodyw Mov Ther. 2015;19(1):102-12.

14. Rocha T, Souza H, Brandao DC, Rattes C, Ribeiro L, Campos SL, et al. The manual diaphragm release technique improves diaphragmatic mobility, inspiratory capacity and exercise capacity in people with chronic obstructive pulmonary disease: a randomised trial. Journal of physiotherapy. 2015;61(4):182-9.

15. González-Álvarez FJ, Valenza MC, Torres-Sánchez I, Cabrera-Martos I, Rodríguez-Torres J, CastelloteCaballero Y. Effects of diaphragm stretching on posterior chain muscle kinematics and rib cage and abdominal excursion: a randomized controlled trial. Braz J Phys Ther. 2016;20(5):405-11.

16. Raine S, Twomey LT. Head and shoulder posture variations in 160 asymptomatic women and men. Arch Phys Med Rehabil. 1997;78(11):1215-23.

17. Halim NHAbA, NSb B, Mohan MN V, editors. Influence of Cervical Posture on Breathing Pattern and Chest Expansion Among Neck Pain Population. The 5th Annual International Conference; 2016.

18. Mohan V, Dzulkifli NH, Justine M, Haron R, Rathinam C. Intrarater reliability of chest expansion using cloth tape measure technique. Bangladesh Journal of Medical Science. 2012;11(4):307-11.

19. Ghasemi F, Yoosefinejad AK, Pirouzi S, Ghaem H. Evaluating the cross-cultural adaptation, reliability, and validity of the Persian versions of the copenhagen neck function disability scale and neck bournemouth questionnaire. Spine. 2019;44(2):E126-E32.

20. Alfawaz AA, Alanazi SS, Almoshari AM, Alzobaidi SA, Alamri YH, Alshwaiman SS, et al. The Effectiveness of Manual Therapy and Exercise Therapy in Treating Non-specific Neck Pain Patients. Journal of Complementary and Alternative Medical Research. 2018:1-32.

21. Ylinen J. Physical exercises and functional rehabilitation for the management of chronic neck pain. Europa medicophysica. 2007;43(1):119.

22. McCoss CA, Johnston R, Edwards DJ, Millward C. Preliminary evidence of Regional Interdependent Inhibition, using a 'Diaphragm Release'to specifically induce an immediate hypoalgesic effect in the cervical spine. J Bodyw Mov Ther. 2017;21(2):362-74.

23. Lee K-Z, Fuller DD. Neural control of phrenic motoneuron discharge. Respir Physiol Neurobiol. 2011;179(1):71-9.

24. Chou Y-L, Davenport PW. Phrenic nerve afferents elicited cord dorsum potential in the cat cervical spinal cord. BMC Physiol. 2005;5(1):7.

25. Zhang W, Davenport PW. Activation of thalamic ventroposteriolateral neurons by phrenic nerve afferents in cats and rats. J Appl Physiol. 2003;94(1):220-6.

26. Marizeiro DF, Florêncio ACL, Nunes ACL, Campos NG, de Paula Lima PO. Immediate effects of diaphragmatic myofascial release on the physical and functional outcomes in sedentary women: a randomized placebo-controlled trial. J Bodyw Mov Ther. 2018;22(4):924-9.

27. Yozbatiran N, Gelecek N, Karadibak D. Influence of physiotherapy programme on peak expiratory flow rate (PEFR) and chest expansion in patients with neck and low back pain. Journal of Back Musculoskeletal Rehabilitation. 2006;19(1):35-40.

28. Joshi S, Sheth M. Effect of McKenzie Self-Therapy Protocol on Forward Head Posture and Respiratory Functions of School Going Adolescent Girls. International Journal of Health Sciences Research. 
2019;9(12):293-8.

29. Sheikhhoseini R, Shahrbanian S, Sayyadi P, O'Sullivan K. Effectiveness of therapeutic exercise on forward head posture: a systematic review and meta-analysis. J Manipulative Physiol Ther. 2018;41(6):530-9.

30. Kapreli E, Vourazanis E, Billis E, Oldham J, Strimpakos N. Respiratory dysfunction in chronic neck pain patients. A pilot study. Cephalalgia. 2009;29(7):701-10.

31. Wirth B, Amstalden M, Perk M, Boutellier U, Humphreys B. Respiratory dysfunction in patients with chronic neck pain-Influence of thoracic spine and chest mobility. Man Therap. 2014;19(5):440-4.

32. Kang J-I, Jeong D-K, Choi H. Correlation between pulmonary functions and respiratory muscle activity in patients with forward head posture. Journal of physical therapy science. 2018;30(1):132-5.

33. Singla D, Veqar Z. Association between forward head, rounded shoulders, and increased thoracic kyphosis: a review of the literature. Journal of chiropractic medicine. 2017;16(3):220-9.

\section{Figures}




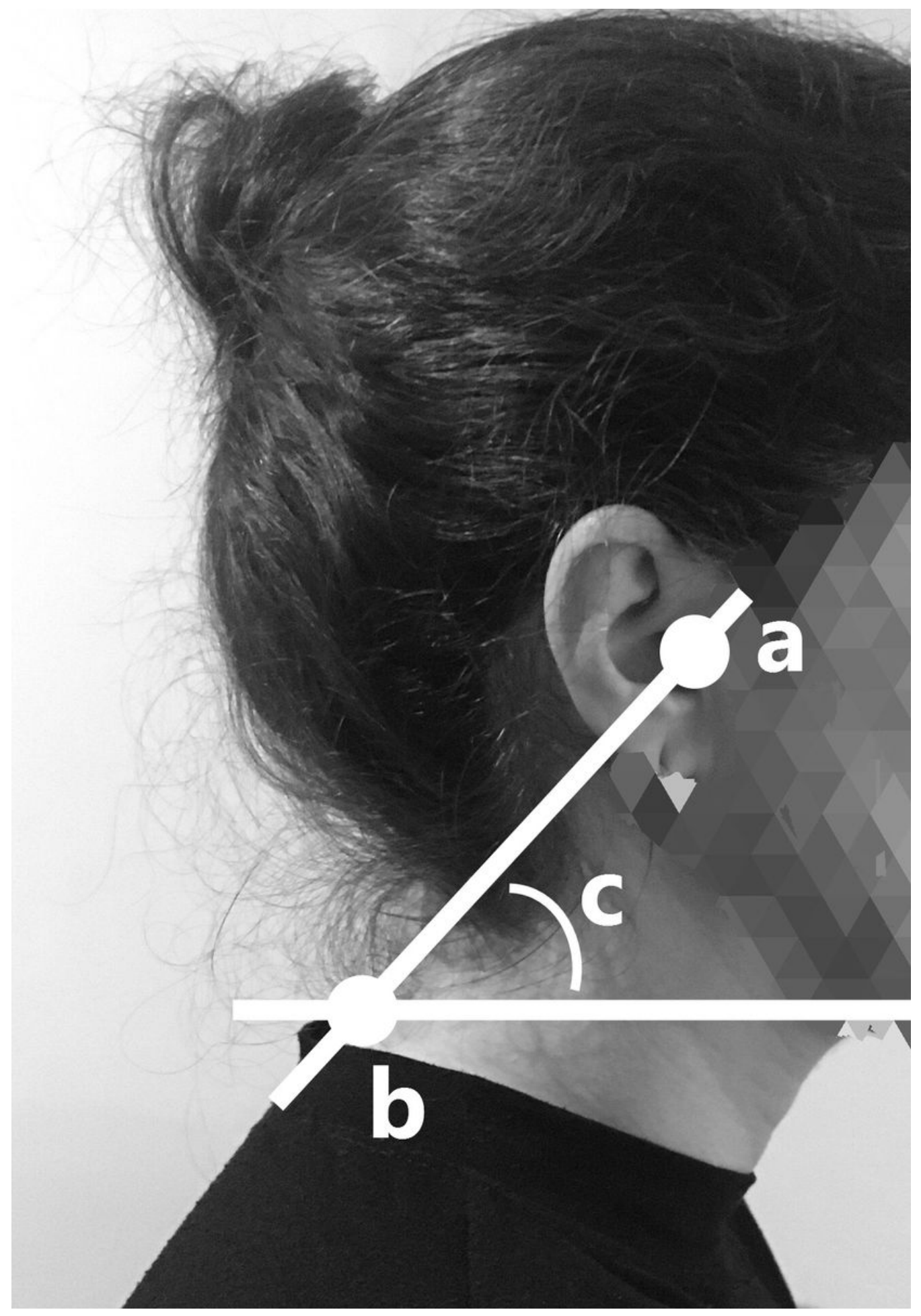

Figure 1

Craniovertebral angle. a: tragus; b: C7 spinous process; c: Craniovertebral angle. 


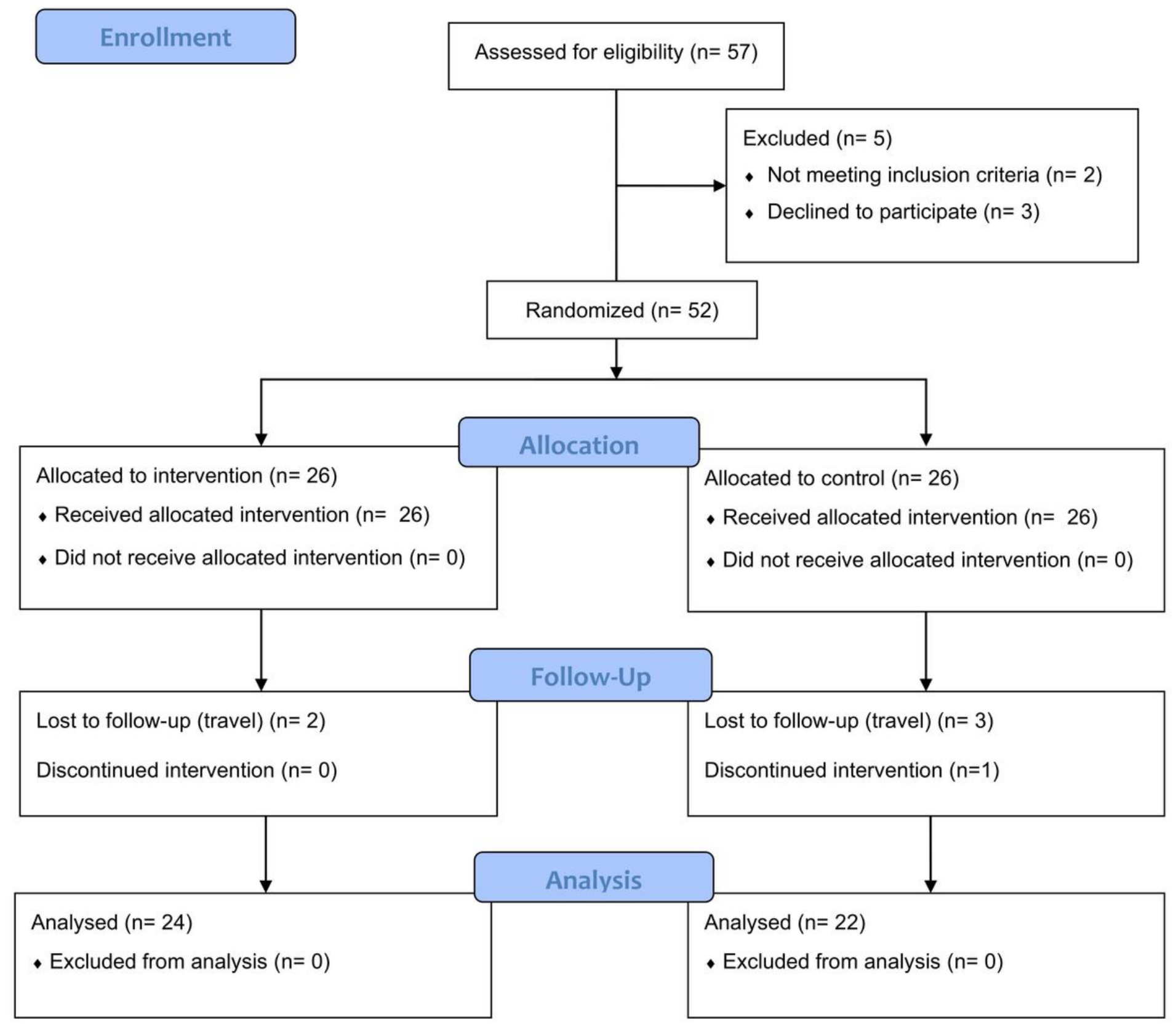

\section{Figure 2}

CONSORT flow diagram.

\section{Supplementary Files}

This is a list of supplementary files associated with this preprint. Click to download.

- CONSORT2010Checklist.doc

- manuscriptsubmitv2.pdf 